\title{
Oral health amongst male inmates in Saudi prisons compared with that of a sample of the general male population
}

SADJ October 2017, Vol 72 no 9 p402 - p407

RMF Bukhari ${ }^{1}$, AMH Al-Sulaimi ${ }^{2}$, AH Fadaak ${ }^{3}$, AA Balhaddad ${ }^{4}$, AMA AlKhalfan $^{5}$, MMA El Tantawi $^{6}$, AA Al-Ansari $^{7}$

\begin{abstract}
Objectives: A survey compared dental caries experience, perceived problems, treatment needs and exposure to risk factors in a group of prisoners in two Saudi prisons with those of a group from the general population.
\end{abstract}

Methods: The study included male prisoners $(\mathrm{n}=82)$ in Dammam and Khobar prisons (October 2014- January 2015) An age, gender and education-matched control group ( $n=79)$ was selected from literacy schools and an elderly care home using a stratified sampling method. Data was collected on an interview questionnaire. Caries experience was assessed using World Health Organization criteria.

Results: Of the prisoners, $75.6 \%$, and, of the subjects in the control group, $47.4 \%$, reported smoking cigarettes daily, $95.1 \%$ and $70.9 \%$ reported having oral health problems such as dental pain or bleeding on brushing whilst $97.6 \%$ and $70.9 \%$ reported treatment need, with caries incidence being around $90.2 \%$ and $57 \%$. Being a prisoner increased the odds of having dental problems affecting daily activities (odds ratio= 7.37), and having decayed teeth (odds ratio= 6.99).

Conclusions: Male inmates in the two Saudi prisons had higher odds of dental problems than did subjects from the general population. Governmental action and volunteering

1. Ryan MF Bukhari: BDS. Johns Hopkins Aramco Health care.

2. Abdulrahman $\mathbf{M H}$ Al-Sulaimi: BDS. College of Dentistry, University of Dammam, Dammam, Saudi Arabia.

3. Ahmed H. Fadaak: BDS. College of Dentistry, University of Dammam, Dammam, Saudi Arabia.

4. Abdulrahman Balhaddad: $B D S, M S D$. College of Dentistry, University of Dammam, Dammam, Saudi Arabia, Indiana University, School of Dentistry, Indianapolis, Indiana, USA.

5. Ali M A AlKhalfan: BDS. College of Dentistry, University of Dammam, Dammam, Saudi Arabia.

6. Maha M A El Tantawi: MS, PhD. College of Dentistry, University of Dammam, Dammam, Saudi Arabia.

7. Asim A. Al-Ansari: $M S, D S c D$. College of Dentistry, University of Dammam, Dammam, Saudi Arabia.

Corresponding author

Abdulrahman Balhaddad:

Tel: +1-317-737-4315 or +966500507689

E-mail: aabalhaddad@hotmail.com

\section{ACRONYM}

KSA: Kingdom of Saudi Arabia

initiatives are needed to reduce oral health inequalities between prisoners and the general population.

\section{INTRODUCTION}

Prisoners have high rates of chronic and blood-borne diseases, mental and psychological illnesses and dental diseases. ${ }^{1}$ They usually come from disadvantaged groups with less education, higher unemployment rates and lower chances of adopting healthy practices and having access to and seeking health care to them. Further, their disease risk increases because of health damaging practices such as the use of tobacco, alcohol and substance abuse. ${ }^{2}$ At the time of their admission to prison, convicts usually already present with a considerable amount of unmet dental treatment needs 2,3 which are unlikely to receive the required attention. This latter situation could be attributed to a lack of resources for dental treatment in the prison health care system or perhaps, to an unwillingness on the part of dentists to deal with the high security constraints in the prison environment. In addition, dentists are usually attracted to the more financially rewarding private practice environment. ${ }^{3,4}$

Several countries have instituted programs to manage the oral health of prisoners. ${ }^{5,8}$ Around the world, studies have been conducted to assess the oral health status and needs presented by prisoners, and to facilitate planning for the required manpower to provide the required services. Examples include the United States, ${ }^{9,10}$ Australia, ${ }^{11}$ Europe, ${ }^{4,12}$ China $^{13}$ and South Africa. ${ }^{14}$

In Saudi Arabia, the General Directorate of Prisons supervises 116 prisons and reformatories with a population estimated to include 47,000 prisoners, of whom $72 \%$ are foreigners (www.prisonstudies.org/country/saudi-arabia). There are inadequate data about the oral health status and needs of prisoners in the Middle East, including the Kingdom of Saudi Arabia (KSA). If the oral health situation of the general population in other Middle Eastern countries were to be extrapolated for the purpose of comparison to the situation of inmates in Saudi prisons, differences in health care systems, cultural norms and ethnic 
backgrounds would limit the usefulness of that endeavour. The present study assessed dental caries experience, exposure to risk factors and access to care among a group of prisoners in two prisons in the Eastern Province of KSA; Dammam and Khobar, and compared that data with matching information from a general population group. The comparison may assist in the determination of the resources required to attend to the oral health needs of prisoners.

\section{METHODS}

A study of cross sectional design compared data representing a group of male prisoners to matching data from a selected group representing the general population. Sample size was estimated using the following assumptions: 5\% type I error, 20\% type II error, $80 \%$ prevalence of dental pain among prisoners and $60 \%$ among the group representing the general population. Calculations (MedCalc software, MariaKerke, Belgium) estimated that 78 subjects would be needed per group with a total of 156 to validate the study.

\section{Recruitment}

Study Group: Prisoners were recruited from Dammam and Khobar, two prisons in the Eastern Province having a capacity of approximately 3,350 inmates. Khobar prison has recently been renovated to only a male section whereas Dammam prison included both male and female sections. Following cultural norms, the male examiners were allowed to examine male prisoners only and female prisoners were not included in the study. To maintain the confidentiality of the prisoners, the prison authorities, not the investigators, selected a convenience sample. Hence, a true random sampling strategy was not possible. Subjects were included from all sections and wards except the quarantine. Informed consent was obtained from all participants. Study data were collected from the prisoners and preliminary analysis was conducted to provide descriptive information.

Control Group: A comparable group was selected from the general population to match the mean age, gender and distribution of educational levels of prisoners (groupmatching). Subjects for the comparison group were selected from amongst the communities of three schools of literacy and of a home for the care of the elderly, in Dammam and Khobar. The managers invited subjects who were free and/ or willing to participate in the study. Subjects were informed that the participation in this study was optional and each had the right to withdraw at any time. Thus, subjects in the comparison group were selfselected volunteers. Data was collected from October 2014 to January 2015.

Ethical Approval

Institutional Review Board approval was obtained (IRB/2015/02/016). The study was conducted according to the Principles of the Helsinki declaration. A letter explaining the purpose of the study and requesting permission to proceed was sent to the prisons authorities and to the managers of the schools of literacy and the care facility.

\section{Background}

Both prisons have dental clinics, that at the Khobar prison clinic being recently installed. A dentist from the Ministry of Interior visited the Dammam Prison clinic weekly with a total of 0.2 full-time equivalent (FTE) dentists for both prisons. No dentist had yet visited Khobar prison. The study procedures were performed in the respective clinics. The managers of the Schools of Literacy and the Elderly Care Facility provided accommodation, such as a classroom or any open space, for the study team to conduct the examination.

Members of the study team explained the purpose of the study and submitted the official request to the facility's authorities/ managers, with whom the flow of subjects was planned. Participants were brought into the designated area in groups of two to four. Each subject was introduced to the study, signed the consent form, was interviewed, and clinically examined.

\section{Questionnaire}

An interview-based questionnaire was used to minimize the potential effect of illiteracy or language barriers. Collected were background information (age, education and time since imprisonment), exposure to risk factors (frequency of tooth brushing, use of fluoridated toothpaste, number of cigarettes smoked daily and use of chewing tobacco) and accessibility to care, in addition to self-reported oral health problems (oral problems in general, dental pain and bleeding on brushing) and perceived need for care. The same questionnaire was used for the comparison group after removing the question about duration of imprisonment.

\section{Clinical Examination}

Disposable mirrors and probes were used for the examination which was conducted under head light. Training and calibration for caries assessment was done to ensure reliability among examiners. Clinical examination assessed caries at the cavitation level using the World Health Organization (WHO) criteria $^{15}$ and the DMFT was recorded. Kappa statistic for reliability between the two examiners (R.B and A.S) was 0.7. The other three investigators recorded the results of clinical examinations, interviewed the participants using the questionnaire, managed the flow of subjects and performed the infection control procedures. The inter-examiner agreement for identification of gingivitis and suspicious oral lesions produced kappa values of 0.35 and 0.27 respectively. These values are quite low and these date were omitted from the examination to ensure validity.

After data were collected, subjects were made aware of their treatment needs. Volunteering dentists from the College arranged a subsequent visit, which was not a part of this study, to respond to the treatment needs. This was not an incentive to influence the participation in the study as the treatment was arranged after the study had been conducted.

Data Analysis

Using Chi square, the two groups were compared regarding background variables (age and education), frequency of daily brushing, use of fluoridated tooth paste, daily cigarette smoking, using chewing tobacco, caries experience, dental pain, problems affecting daily activities, perceived need for treatment, bleeding on brushing, having decayed, missing, filled teeth. Comparisons regarding the number of cigarettes smoked daily, time since last dental visit, number of decayed, missing or filled teeth was done using the Mann Whitney $\mathrm{U}$ test. Correlation between time since imprisonment and the number of decayed, missing or filled teeth as well as 
time since last dental visit was assessed using Spearman rho. Binary logistic regression analysis assessed the effect of various independent variables on two dependent variables (having dental problem affecting daily activities and having decayed teeth). Factors with significant effect in univariate regression were entered into multivariate logistic regression and the odds ratio and confidence intervals were calculated. Significance level was set at 5\%. Statistical analysis was done using SPSS version 17.0.

\section{RESULTS}

Questionnaire and clinical examination data were available for 161 subjects (82 prisoners and 79 subjects in the comparison group). These represented $98.8 \%$ and $100 \%$ of those initially consenting to participate as one prisoner left the study. Some prisoners refused to complete some items in the questionnaire. These unanswered items were dropped during data analysis. The two groups were similar in age, gender and education ( $p=0.10$ and 0.35 respectively, Figure 1). The median duration since imprisonment was 27 months (ranging from 2 to 360 months).

Oral Hygiene Practice

The two groups had similar oral hygiene practices includ-

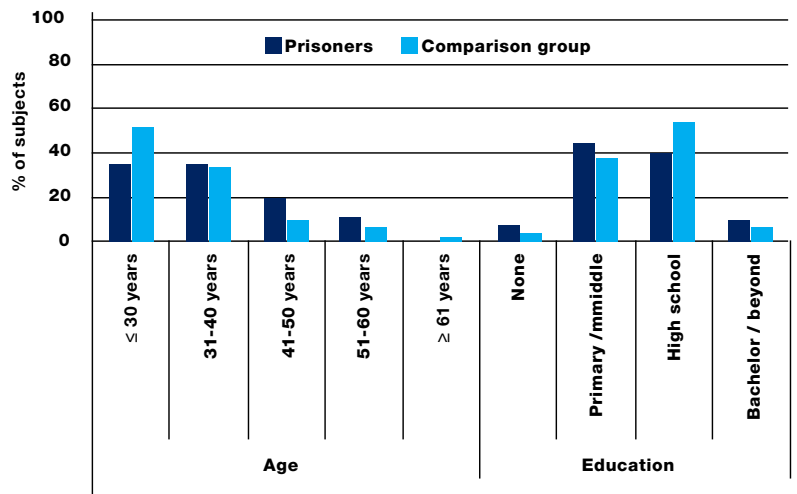

Figure 1: Comparison between the two study groups in age and education

ing brushing frequency and use of fluoridated toothpaste $(P=0.14$ and 0.68 , Table 1). Daily smoking of cigarettes was higher in prisoners' group with a greater median number of cigarettes $(75.6 \%$ and $47.4 \%$, median $=20$ and $0, P<0.0001$ and 0.004 , Table 1). The frequency of using chewing tobacco in the two groups was similarly low (Table 1). Prisoners reported a much longer period since the last dental visit than did subjects in the comparison group (median $=24$ and 12, $\mathrm{P}<0.0001)$. Time since last dental visit was significantly, moderately and positively correlated with length of imprisonment $(\mathrm{rho}=0.41$, $\mathrm{P}=$ 0.001). Prisoners reported a greater frequency of having oral health problems, dental pain, dental problems affecting daily activities and need for treatment than those in the comparison group (Table 2). There was no statistically significant difference between the two groups in reporting bleeding on brushing $(p=0.98$, Table 2)

\section{Caries Experience}

Table 3 shows the comparison between the two study groups in caries experience. The percentage of prisoners with decayed or missing teeth was significantly higher than the comparison group. A significantly higher median number of teeth with caries experience was found in prisoners compared with the control group (median $=8$ and $5, P=0.001$ ), although the percentage of subjects with caries experience in the two groups was similar $(P=0.27)$. Correlation between time in months since imprisonment and number of decayed and missing teeth was not statistically significant but was weakly positive (rho $=0.11$ and $0.15, P=0.32$ and 0.17). Correlation with number of filled teeth was not statistically significant and weakly negative $(\mathrm{rho}=-0.02, \mathrm{P}=0.84)$

\section{Dental Problem in Relation to Daily Activities}

"Having a dental problem affecting daily activities" was significantly related to the prisoners group, education, the number of cigarettes smoked daily and having decayed teeth. In addition, "having decayed teeth" was significantly associated with prisoners (Table 4). In multivariate logistic regression analysis, when all four significant factors related to having a dental problem affecting daily activities were considered, the only factor with a significant effect was being a prisoner (odds ratio $=7.37$, confidence interval= $3.60,15.07)$. Being a prisoner also increased the odds of having decayed teeth seven - times (odds ratio $=6.99$, confidence interval $=2.97,16.43$ ).

\section{DISCUSSION}

One of the strengths of the present study is that it compares the findings among prisoners to a concurrent, age-, genderand education- matched comparison group representing the general population. Endeavours were made to control the confounding effect of education (as an indicator of socio-economic status) on oral health problems/caries. This was done partly during study design (matching) and partly through analysis (multivariate regression). In their 2008 review, Walsh et $\mathrm{al}^{3}$ indicated that most studies

\begin{tabular}{|c|c|c|c|c|}
\hline \multicolumn{2}{|c|}{ Variables } & \multirow{3}{*}{$\begin{array}{l}\text { Prisoners } \\
\text { (N= 82) } \\
49(59.8 \%) \\
33(40.2 \%)\end{array}$} & \multirow{3}{*}{$\begin{array}{l}\text { Comparison } \\
\text { group ( } \mathrm{N}=79) \\
56(70.9 \%) \\
23(29.1 \%)\end{array}$} & \multirow{3}{*}{$\begin{array}{l}P \text { value } \\
0.14\end{array}$} \\
\hline \multirow{2}{*}{$\begin{array}{l}\text { Brushing frequency } \\
\text { Daily }\end{array}$} & Daily: n (\%) & & & \\
\hline & Less frequently: $\mathrm{n}(\%)$ & & & \\
\hline \multirow{3}{*}{$\begin{array}{l}\text { Using fluoridated } \\
\text { tooth paste }\end{array}$} & Yes: n (\%) & $26(39.4 \%)$ & \multirow{3}{*}{$\begin{array}{c}30(44.1 \%) \\
9(13.2 \%) \\
29(42.6 \%)\end{array}$} & \multirow{3}{*}{0.68} \\
\hline & No: n (\%) & 7 (10.6\%) & & \\
\hline & Do not know: n (\%) & 33 (50\%) & & \\
\hline \multirow{2}{*}{$\begin{array}{l}\text { Smoking cigarettes } \\
\text { daily }\end{array}$} & Yes: n (\%) & $62(75.6 \%)$ & $37(47.4 \%)$ & \multirow{2}{*}{$<0.0001^{*}$} \\
\hline & No: n (\%) & $20(24.4 \%)$ & 41 (52.6\%) & \\
\hline \multirow{2}{*}{$\begin{array}{l}\text { Number of cigarettes } \\
\text { smoked daily }\end{array}$} & Min - max & $0-60$ & $0-50$ & \multirow{2}{*}{$0.004^{*}$} \\
\hline & Median & 20 & 0 & \\
\hline \multirow{2}{*}{$\begin{array}{l}\text { Using chewing } \\
\text { tobacco }\end{array}$} & Yes: n (\%) & $2(2.4 \%)$ & 7 (8.9\%) & \multirow{2}{*}{0.10} \\
\hline & No: n (\%) & $80(97.6 \%)$ & 72 (91.1\%) & \\
\hline \multirow{2}{*}{$\begin{array}{l}\text { Time in months since } \\
\text { last visit to dentist }\end{array}$} & Min - max & $0.2-120$ & $0.2-120$ & \multirow{2}{*}{$<0.0001^{\star}$} \\
\hline & Median & 24 & 12 & \\
\hline
\end{tabular}

*Statistically significant at $\mathrm{P} \leq 0.05$ 
assessing oral health among prisoners used samples from previous national surveys as comparison groups. In other studies, comparison groups already existed or were matched by age or ethnic group. Less frequently, some studies assessed the effect of socio-economic conditions on oral health status among prisoners. ${ }^{4,9,16}$

\begin{tabular}{|c|c|c|c|c|}
\hline \multicolumn{2}{|l|}{ Variables } & $\begin{array}{l}\text { Prisoners } \\
(\mathrm{N}=82)\end{array}$ & $\begin{array}{l}\text { Comparison } \\
\text { group }(\mathrm{N}=79)\end{array}$ & $P$ value \\
\hline \multirow{2}{*}{ Oral health problems } & Yes & 78 (95.1\%) & 56 (70.9\%) & \multirow{2}{*}{$<0.0001^{\star}$} \\
\hline & No & $4(4.9 \%)$ & $23(29.1 \%)$ & \\
\hline \multirow{2}{*}{ Dental pain } & Yes & $72(87.8 \%)$ & $39(49.4 \%)$ & \multirow{2}{*}{$<0.0001^{*}$} \\
\hline & No & $10(12.2 \%)$ & $40(50.6 \%)$ & \\
\hline \multirow{2}{*}{$\begin{array}{l}\text { Dental problem affecting } \\
\text { daily activities }\end{array}$} & Yes & $66(80.5 \%)$ & 28 (35.4\%) & \multirow{2}{*}{$<0.0001^{*}$} \\
\hline & No & $16(19.5 \%)$ & $51(64.6 \%)$ & \\
\hline \multirow{2}{*}{ Perceived need for treatment } & Yes & $80(97.6 \%)$ & $56(70.9 \%)$ & \multirow{2}{*}{$<0.0001^{\star}$} \\
\hline & No & $2(2.4 \%)$ & $23(29.1 \%)$ & \\
\hline \multirow{2}{*}{ Bleeding on brushing } & Yes & $38(57.6 \%)$ & $39(57.4 \%)$ & \multirow{2}{*}{0.98} \\
\hline & No & 28 (42.4\%) & $29(42.6 \%)$ & \\
\hline
\end{tabular}

*: Statistically significant at $\mathrm{P} \leq 0.05$
Prisoners were included in the study using a convenience sample since the study team did not have the relevant comprehensive administrative information, which made random sampling difficult. The same limitation related to unavailability of data was cited in another study assessing oral health status among English prisoners. ${ }^{5}$ The convenience sampling in the present study may have limited the extent to which the sample represents prisoners in Saudi prisons and, consequently, generalizability. However, consider that in most prisons, essentially the same exposure to risk factors prevails among inmates after admission. Higher odds of oral diseases compared with the general population are expected to occur in various prisons in KSA. Variations in the magnitude of these odds may, however, exist among the different locations. Thus, although generalization may suffer due to the non-statistical nature of the samples included in the study, the conclusions would logically apply in various locations unless mitigating factors intervene. Another limitation that may be related to convenience sampling is the potential for overestimation of perceived and/or actual needs if the prisoners selected by the prisons' authorities actually volunteered to join the study, seeking diagnosis and hoping for treatment. However, this would have been balanced to some extent by the percentage of prisoners with actual needs who refused to participate when they knew that only examination and no actual treatment would be provided during the study period. This latter situation was also reported in studies among English prisoners. ${ }^{2,17}$

The 2010 official Saudi census indicated that expatriates represent $31 \%$ of the total population in KSA. ${ }^{18}$ The actual percentage of expatriates in the prisoners' sample is not known since no data could be obtained regarding their nationality. On the other hand, the comparison group representing the general population contained only Saudis. It is not known what proportion of the higher odds of oral health problems among prisoners may be attributed to their nationality/ ethnic background and how much is related to factors associated with their imprisonment. The aim of the study was to provide information about the oral health status of prisoners in KSA. Comparing prisoners with another group could be beneficial to investigate any factors that might affect the oral health status of prisoners. Also, this comparison might be helpful to influence health care policy planners responsible for prison health programs. What 
the findings of the study show is that prisoners, regardless of their nationalities and ethnic backgrounds, have higher odds of oral health problems than does the general Saudi population who has reasonable access to care. Providing health care to this high risk group in a defined and limited setting such as the prison potentially decreases inequalities in access to care.

In the present study, self-reporting was exclusively used to assess exposure to risk factors and perceived oral health problems while clinical examination was used to assess caries status. It is agreed that self-reporting can be used to identify high-risk groups with health needs. ${ }^{4}$ However, this may potentially introduce the risk of overestimation since prisoners may exaggerate the extent of their suffering to gain attention and priority over their colleagues for treatment. No other means of collecting information about exposure to risk factors was feasible for the study purposes. In addition, the validity of self-reporting by prisoners was confirmed by the clinical assessment of caries by the examiners which increases the credibility of the obtained data. Other oral health conditions (gingival and periodontal status as well as oral mucosal lesions) were not assessed because of logistic constraints related to the limited time allowed by the prison authorities for the visit and examination. In addition, kappa values were not satisfactory for the data reflecting gingivitis and suspicious oral lesions. It would be useful to include an assessment of these aspects of oral health in future studies.

The percentage of daily tooth brushing in the two groups was generally lower than that reported in another study of Saudis from the general population, although the authors in that study presented their results categorized by educational levels with no overall figures reported for the group as a whole, which makes direct comparison difficult.19 It was, however, higher than that reported among a convenience sample of male and female Saudis, also representing the general population in another study, where $46 \%$ were tooth brush users. ${ }^{20}$ Similar levels of brushing were reported among prisoners in other studies. ${ }^{1,2}$

The median percentage of cigarette smoking among prisoners and subjects in the comparison group was higher than that stated in Bassiony's review, 22,6\%,, ${ }^{21}$ Moreover, the WHO reported that the percentage of tobacco use in KSA is 35\%, which is less than that found in this study (75\%). ${ }^{22}$ On the other hand, smokeless tobacco use among prisoners in the current study was lower than that among the comparison group. The figures related to smokeless tobacco in the present study may reflect the actual situation or may be due to under-reporting to avoid penalties imposed by the prison authorities which ban smokeless tobacco but not cigarettes. The latter interpretation may be supported by the fact that the examiners noticed traces of the effects of smokeless tobacco in some inmates during caries examination although they denied using it in the interview. The high levels of smoking reported in the present study is similar to other studies conducted among prisoners., ${ }^{1,23-25}$ This situation calls for interventions aiming at cessation of tobacco habits to control deleterious effects on oral and general health. These interventions should be part of the plans of the prison authorities and should be implemented on an ongoing basis.
The median time since last dental visit among prisoners was two years, and it was also the median time since imprisonment. This is to be expected since only $0.2 \mathrm{FTE}$ dentists were assigned to provide care to 3,350 prisoners. Consequently, almost all prisoners reported they needed dental treatment. Other studies reported high dental treatment needs among prisoners (the level in the present study is much higher). ${ }^{2,7,26}$ At an lowa correctional facility that housed 8,700 prisoners, it was estimated that 14 FTE dental staff (dentists and others) would be needed to address the dental needs of the prisoners. ${ }^{26}$ Dentistto-inmates ratio in various states in the US ranged from 1: 1,397 to 1: 1,031.6 These figures represent systems where dental needs can be met to a greater extent than the situation reported in the current study. On the other hand, inadequacy of a supply of dentists to meet the needs of prisoners was reported in other settings with different health care systems such as among Indian prisons. ${ }^{1}$ It is understandable that dental services can be made available to prisoners to an extent less than to the general population, due to issues of logistics, high mobility of subjects and manpower shortage. ${ }^{6}$ Acknowledging these constraints, the amount of unmet treatment needs reported among prisoners in the present study is still markedly greater relative to the comparison group so that being a prisoner was associated with a sevenfold odds of having problems affecting daily activities and having caries.

Almost nine out of ten prisoners reported having dental pain. In another study, high level of reported pain among prisoners was considered untrue since some subjects may try to gain access to care. ${ }^{27}$ Alternatively, it is possible that the reported level of dental pain reflects an actual state of greater dental disease which may be supported by the high level of caries detected by clinical examination. ${ }^{16}$

In the present study, the prevalence and severity of decayed and missing teeth in prisoners was higher than that in subjects from the general population. Filled teeth, on the other hand, had lower prevalence and intensity. This situation is similar to that reported by most studies assessing the oral health of prisoners. ${ }^{1,2,9,24,28}$ DMFT was not significantly affected by the duration of imprisonment which supports the concept that imprisonment itself is not the cause of worse oral health status among prisoners, but rather the accumulated effect of their previous lifestyle, exacerbated by inadequate oral health care in prison. This finding is similar to those of a study conducted among Italian prisoners. ${ }^{4}$ In another study, however, DMFT increased as the term of imprisonment increased except for the number of decayed teeth. ${ }^{1}$ The authors attributed this to worse detention conditions among prisoners with long term or life imprisonment which further impacts their sociological and psychological problems. ${ }^{1}$ In contradiction, another study reported a positive relation between time since imprisonment and caries experience, with a longer stay in prison associated with better oral health. ${ }^{29}$ This may be expected when there are established oral health care systems that prisoners can increasingly use as more time passes in prison. Better access to care and reduced exposure to harmful practices and risk factors inside the prison would decrease the incidence of disease, ${ }^{1,2}$

The oral health needs of prisoners should be assessed by a qualified dental team. Bose and Jenner stated that oral health care of prisoners could be maintained by 
providing free fluoride supplements, information about dental service, reducing cariogenic food inside prisons, training prison staff in health promotion, addressing problems of smoking, alcohol and drugs misuse. ${ }^{30}$ The inadequate numbers of dentists available to provide care for prisoners calls for a greater government support for oral health care services in prisons to alleviate the disease burden among this at-risk group. Ensuring regular access to care decreases human suffering, cost of treatment and inequalities in oral health. Innovative solutions may include the collaboration of non-governmental organizations with the academic sector to offer volunteer services and extend to extra-mural training opportunities for students in the clinics of the prisons.

\section{CONCLUSION}

The results of this study indicated that the prisoners surveyed were more likely to have dental problems than individuals from the general population. The administrators of prisons should have a qualified dental team who is able to provide an optimum dental treatment to prisoners to maintain their oral health. Further studies are required to address the limitations of this study, to specifically investigate the range of individual risk factors affecting inmates, and to formulate preventive and interceptive plans to ensure the oral wellbeing of this group.

\section{References}

1. Reddy V, Kondareddy C, Siddanna S, Manjunath M. A survey on oral health status and treatment needs of life-imprisoned inmates in central jails of Karnataka, India. Int Dent $\mathrm{J}$ 2012;62:27-32.

2. Heidari E, Dickinson C, Wilson R, Fiske J. Oral health of remand prisoners in HMP Brixton, London. $\mathrm{Br}$ Dent $\mathrm{J}$ 2007;202:5-5.

3. Walsh T, Tickle M, Milsom K, Buchanan K, Zoitopoulos L. An investigation of the nature of research into dental health in prisons: a systematic review. Br Dent J 2008;204:683-9.

4. Nobile CG, Fortunato L, Pavia M, Angelillo IF. Oral health status of male prisoners in Italy. Int Dent J 2007 Feb;57:27-35.

5. Kipping RR, Scott P, Gray C. Health needs assessment in a male prison in England. Public Health 2011; 125:229-33.

6. Makrides NS, Shulman JD. Dental health care of prison populations. J Correct Health Care 2002; 9:291-306.

7. Harvey S, Anderson B, Cantore S, King E, Malik F. Reforming prison dental services in Eng $\neg$ land. A guide to good practice. August 2005. Available at: www.ohrn.nhs.uk/conferences/ past/D160905PCW.pdf Accessed April 12th, 2015.

8. American Civil Liberties Union. Know your right: medical, mental and dental health care. ACLU National Prison Project. Available at: https://www.aclu.org/files/assets/know_your_ rights_--_medical_mental_health_and_dental_july_2012.pdf

9. Boyer EM, Nielsen-Thompson NJ, Hill TJ. A comparison of dental caries and tooth loss for lowa prisoners with other prison populations and dentate U.S. adults. J Dent Hyg 2002; 76: 141-50.

10. Staton M, Leukefeld C, Webster JM. Substance use, health, and mental health: problems and service utilization among incarcerated women. Int $\mathrm{J}$ Offender Ther Comp Criminol 2003; 47: 224-39.

11. Osborn M, Butler T, Barnard PD. Oral health status of prison inmates - New South Wales, Australia. Aust Dent J 2003; 48: 34-8.

12. Lunn H, Morris J, Jacob A, Grummitt C. The oral health of a group of prison inmates. Dent Update 2003; 30: 135-8.

13. McGrath C. Oral health behind bars: a study of oral disease and its impact on the life quality of an older prison population. Gerodontology 2002; 19: 109-14.

14. Naidoo S, Yengopal V, Cohen B. A baseline survey: oral health status of prisoners - Western Cape. SADJ 2005; 60: 24-7.

15. World Health Organization. Oral Health Surveys: Basic Methods. 5th edition. Geneva, WHO, 2013.

16. Badner V. Oral health status among women inmates at Rikers Island Correctional Facility. J Correct Health Care 1994; 1: 55-72.

17. Buchanan KM, Milsom KM, Zoitopoulos L, Pau A, Tickle M. The performance of a screening test for urgent dental treatment need in a prison population. Br Dent J 2008;205:E19.

18. Saudi Gazette. Census shows Kingdom's population at more than 27 million. Nov. 24, 2010. Available at: at http://www. saudigazette.com.sa/index.cfm?method=home.regcon\&c ontentID=2010112487888\&archiveissuedate=24/11/2010). Accessed October 19th, 2014.

19. Al-Otaibi M, Angmar-Månsson B. Oral hygiene habits and oral health awareness among urban Saudi Arabians. Oral Health Prev Dent 2004;2:389-96.

20. Almas K, al-Shammari B, al-Dukhyeel S. Education level, oral hygiene and smoking habits of an elderly Saudi population in Riyadh. Odontostomatol Trop 2003;26 :4-6.

21. Bassiony MM. Smoking in Saudi Arabia. Saudi Med J 2009; 30: 876-81.

22. World Health Organization. WHO report on the global tobacco epidemic, 2012. Country profile: Saudi Arabia. Available at http://www.who.int/tobacco/surveillance/policy/country_profile/sau.pdf. Accessed October 19, 2014.

23. Cropsey KL, Kristeller J. The effects of a prison smoking ban on smoking behavior and withdrawal symptoms. Addict Behav 2005; 30: 589-94.

24. Cropsey KL, Crews KM, Silberman SL. Relationship between smoking status and oral health in a prison population. J Correct Health Care 2006;12:240-8.

25. Dahiya M, Croucher R. Male prisoner tobacco use and oral cancer knowledge : a case study of a local prison in India. Int Dent J 2010; 60: 135-8.

26. Ringgenberg WJ. Initial dental needs and a projection of needed dental capacity in the lowa Department of Corrections. J Correct Health Care 2011;17:150-9.

27. Broderick JE, Schwartz JE, Vikingstad G, Pribbernow M, Grossman S, Stone AAI. The accuracy of pain and fatigue items across different reporting periods. Pain 2008; 139: 146-57.

28. Cavalcanti AL, Rodrigues IS, de Melo Silveira IT, de Oliveira TB, de Almeida Pinto MS, Xavier AF et al. Dental caries experience and use of dental services among Brazilian prisoners. Int J Environ Res Public Health 2014; 11: 12118-28.

29. Jones CM, Woods K, Neville J, Whittle JG. Dental health of prisoners in the North West of England in 2000: literature review and dental health survey results. Community Dent Health 2005; 22: 113-7.

30. Bose A, Jenner T. Dental health in prisons. In: Møller $L$ et al., eds. Health in Prisons: A WHO Guide to the Essentials of Prison Health. Copenhagen, WHO Regional Office for Europe, 2007:147-55. 